\title{
Metallic 2H-Tantalum Selenide Nanomaterials as Saturable Absorber for Dual-Wavelength Q-Switched Fiber Laser
}

\author{
Lingling Yang ${ }^{1}$, Ruwei Zhao ${ }^{1}$, Duanduan $\mathrm{Wu}^{1}{ }^{1}$, Tianxiang $\mathrm{Xu}{ }^{1}{ }^{1} * \mathbb{D}$, Xiaobiao Liu ${ }^{2, *}, \mathrm{Qiuhua} \mathrm{Nie}^{1}$ \\ and Shixun Dai ${ }^{1}$ \\ 1 Laboratory of Infrared Materials and Devices, The Research Institute of Advanced Technologies, \\ Ningbo University, Ningbo 315211, China; 1811082126@nbu.edu.cn (L.Y.); zhaoruwei@nbu.edu.cn (R.Z.); \\ wuduanduan@nbu.edu.cn (D.W.); nieqiuhua@nbu.edu.cn (Q.N.); daishixun@nbu.edu.cn (S.D.) \\ 2 School of Sciences, Henan Agricultural University, Zhengzhou 450002, China \\ * Correspondence: xutianxiang@nbu.edu.cn (T.X.); liuxiaobiao@henau.edu.cn (X.L.); \\ Tel.: +86-574-87609873 (T.X.)
}

\begin{abstract}
A novel 2H-phase transition metal dichalcogenide (TMD)-tantalum selenide ( $\mathrm{TaSe}_{2}$ ) with metallic bandgap structure is a potential photoelectric material. A band structure simulation of $\mathrm{TaSe}_{2}$ via ab initio method indicated its metallic property. An effective multilayered $\mathrm{TaSe}_{2}$ saturable absorber (SA) was fabricated using liquid-phase exfoliation and optically driven deposition. The prepared $2 \mathrm{H}-\mathrm{TaSe}_{2}$ SA was successfully used for a dual-wavelength Q-switched fiber laser with the minimum pulse width of $2.95 \mu$ s and the maximum peak power of $64 \mathrm{~W}$. The repetition rate of the maximum pulse energy of $89.9 \mathrm{kHz}$ was at the level of $188.9 \mathrm{~nJ}$. The metallic $2 \mathrm{H}-\mathrm{TaSe}_{2}$ with satisfactory saturable absorbing capability is a promising candidate for pulsed laser applications.
\end{abstract}

Keywords: $2 \mathrm{H}-\mathrm{TaSe}_{2}$ nano-materials; metallic band structure; saturable absorber; dual-wavelength

\section{Introduction}

The increasing demand for pulsed lasers in the fields of scientific research and industrial processing has motivated researchers to explore a novel saturable absorber (SA). Materials can be divided into three categories depending on carrier concentration, namely, conductors, semiconductors, and insulators. At present, reported insulator SAs only include water [1] and alcohol [2]. The mechanism of saturable absorption is the electronic transition in vibrational energy levels of molecules. However, in-depth studies on insulator SAs are lacking. Related investigations on semiconductor SA have been conducted extensively [3-5]. Numerous SA materials, including SESAM, MXenes, black phosphorus, gold nanorods, and topological insulators, have been proposed to generate pulsed fiber laser. Semiconductor SAs are primarily constrained by their limited operating bandwidth because photon energies should be larger than the material bandgap, but conductor SAs can effectively solve this problem. At present, studies on conductor SAs commonly focus on metal nanoparticles [6,7], nanowires [8,9], and some special transition metal dichalcogenides (TMDs) [10].

TMDs have been regarded as graphene replacements due to their chemical structure of $\mathrm{MX}_{2}$ ( $\mathrm{M}$ and $\mathrm{X}$ denote the transition metal and chalcogen elements, respectively) and outstanding chemical, mechanical, and optoelectronic properties [11]. Given the abundance of M and X, TMDs have a large family with different characters. The chalcogen element $\mathrm{X}$ determines the stability and lattice parameter of TMDs, while the transition metal M influences electronic properties. Hence, TMDs can be categorized as semimetallic, metallic, or even superconducting materials [12,13]. Semiconductive TMDs, such as $\mathrm{MoS}_{2}$, and $\mathrm{WSe}_{2}$, have been extensively investigated [4]. However, metallic TMDs have rarely been explored. As a metallic TMD, $2 \mathrm{H}$-tantalum selenide $\left(\mathrm{TaSe}_{2}\right)$ demonstrates unique magnetic, superconducting, and optical properties. Although the strain-induced ferromagnetism of 
monolayer $\mathrm{TaSe}_{2}$, charge density wave, and functionality in logic circuits and switches have been investigated [14-16], reports on nonlinear optical properties of metallic $2 \mathrm{H}-\mathrm{TaSe}_{2}$ are limited.

The band structure and optical properties of $2 \mathrm{H}-\mathrm{TaSe}_{2}$ were investigated in this study. According to density functional theory, monolayer and multilayer $2 \mathrm{H}-\mathrm{TaSe}_{2}$ materials both exhibit a metallic electronic band structure. The fiber-integrated few-layered $2 \mathrm{H}-\mathrm{TaSe}_{2}$ SA was fabricated using liquid-phase exfoliation and optically driven deposition method. Open-aperture Z-scan measurement examined the saturable absorption property of $2 \mathrm{H}-$ $\mathrm{TaSe}_{2}$. A dual-wavelength Q-switched fiber laser with a pulse energy and peak power of $188.9 \mathrm{~nJ}$ and $64 \mathrm{~W}$, respectively, was demonstrated using the prepared $2 \mathrm{H}-\mathrm{TaSe}_{2} \mathrm{SA}$. The satisfactory nonlinear optical modulating ability of $2 \mathrm{H}-\mathrm{TaSe}_{2}$ proves its potential in novel optoelectronic applications.

\section{Band Structure and Characterization of $\mathrm{TaSe}_{2}-\mathrm{SA}$}

The atomic-layered structure of monolayer $2 \mathrm{H}-\mathrm{TaSe}_{2}$ is illustrated in Figure 1a. Similar to other TMDs, the transition metal (Ta) layer is sandwiched between two chalcogen (Se) layers. Our first-principle calculations were performed using Vienna Ab initio simulation package known as the VASP code [17-19]. The electronic-ion interaction is described using projector-augmented wave method [20]. Energy cutoff of plane waves was set to $520 \mathrm{eV}$. The electron-exchange correlation function was treated using generalized gradient approximation (GGA) in the form proposed by Perdew, Burke, and Ernzerhof (PBE) [21]. Both atomic positions and lattice vectors were fully optimized using conjugate gradient (CG) algorithm with an energy precision of 10-5 eV until the maximum atomic forces are smaller than $0.008 \mathrm{eV} / \AA$. A vacuum region of approximately $15 \AA$ was adapted to eliminate the interaction of two adjacent images. Brillouin zone (BZ) integration was sampled using a $17 \times 17 \times 1 \mathrm{k}$-mesh according to Monkhorst-Pack method [22]. The calculation above confirmed that $2 \mathrm{H}-\mathrm{TaSe}_{2}$ possesses a metallic and electronic band structure, as shown in Figure $1 \mathrm{~b}$. Varying band structures of $2 \mathrm{H}-\mathrm{TaSe}_{2}$ from 4 layers to 7 layers were further calculated using the same method, and the results are illustrated in Figure $2 \mathrm{a}-\mathrm{d}$. The corresponding atomic-layered structures are presented in Figure 2e. The calculated band structures demonstrated a small difference with the results of a previous report [23] because of the different settings in calculation parameters.

(a)

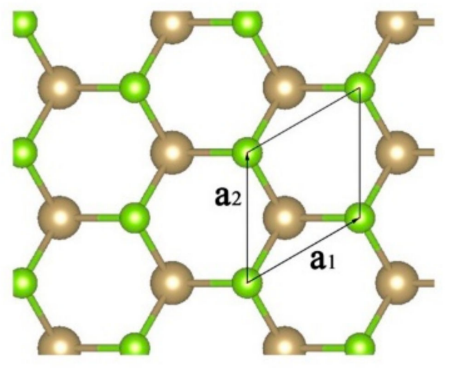

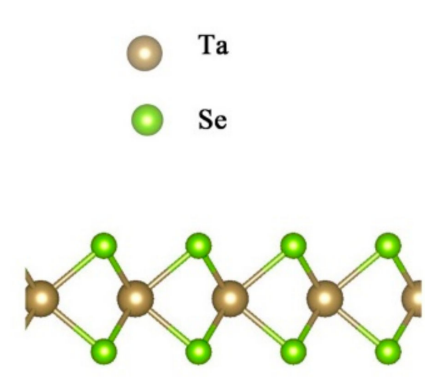

(b)

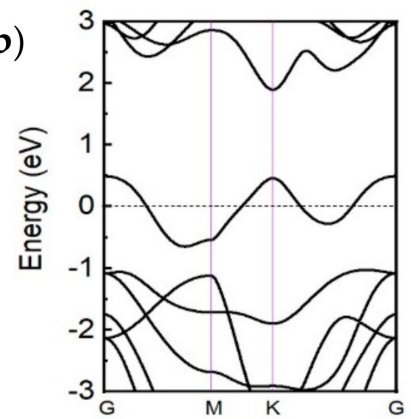

Figure 1. (a) Top (left) and side (right) view of monolayer $\mathrm{TaSe}_{2}$ and (b) band structures of monolayer TaSe $\mathrm{T}_{2}$. Fermi level is set to $0 \mathrm{eV}$. G $(0,0,0), \mathrm{M}(0.5,0,0)$, and $\mathrm{K}(0.333333,0.333333,0)$ represent highly symmetric points in the reciprocal space.

The fiber-integrated few-layered $\mathrm{TaSe}_{2} \mathrm{SA}$ was fabricated using liquid-phase exfoliation and optically driven deposition method. Bulk TaSe ${ }_{2}$ material was grinded into powder for intensive mixing with isopropyl alcohol (IPA). The initial mixture was then sonicated in an ultrasonic bath for approximately $8 \mathrm{~h}$. Notably, this process has a suitable interval to prevent dispersion overheating. Finally, the as-prepared solution was centrifuged at $1500 \mathrm{rpm}$ for $15 \mathrm{~min}$ to separate the large agglomeration, and the upper $\mathrm{TaSe}_{2}$ supernatant was decanted and set aside. 
(a)

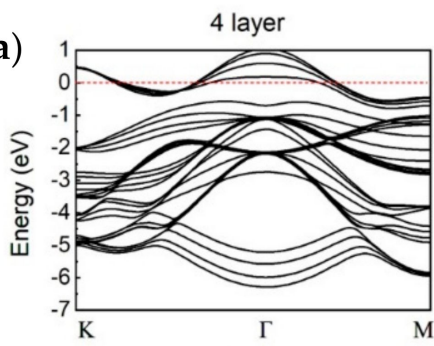

(c)

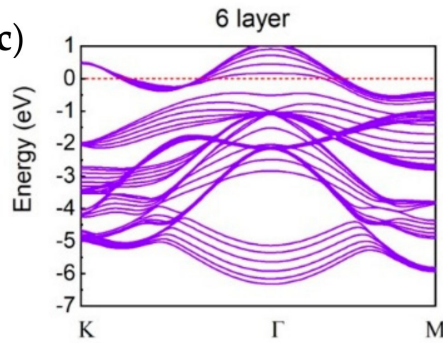

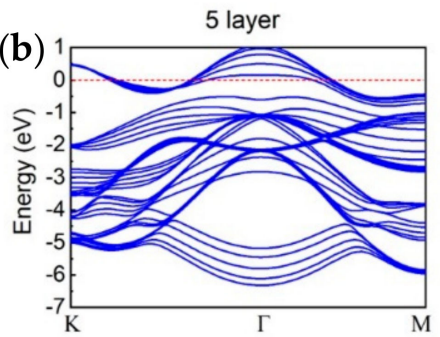

(d)

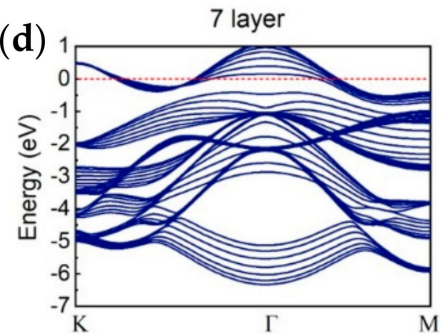

(e)

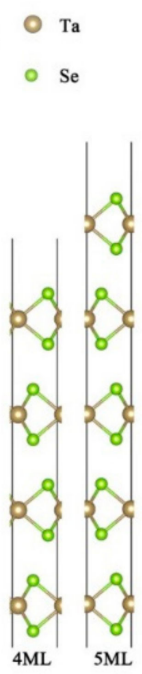

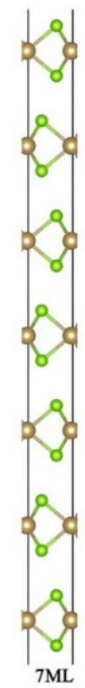

Figure 2. Band structures for multilayer TaSe 2 : (a) four-, (b) five-, (c) six-, and (d) seven-layer $\mathrm{TaSe}_{2}$; (e) corresponding atomic-layered structures of $\mathrm{TaSe}_{2}$.

Homogeneously dispersed solution was dropped on a sapphire substrate to test the characterization of $\mathrm{TaSe}_{2}$ nanosheets conveniently. Then, the substrate was dried under an infrared oven lamp for approximately $5 \mathrm{~h}$ to fabricate the $\mathrm{TaSe}_{2}$ sample. Then the optically driven deposition method was applied to form a fiber-integrated few-layered $\mathrm{TaSe}_{2}$ SA. Light with a wavelength and outpower of $980 \mathrm{~nm}$ and $60 \mathrm{~mW}$, respectively, was directly irradiated onto the fiber. Fiber ferrule was dipped into $\mathrm{TaSe}_{2}$ dispersion for $15 \mathrm{~min}$. After drying for $24 \mathrm{~h}$ at room temperature, the fiber-integrated $\mathrm{TaSe}_{2} \mathrm{SA}$ was formed by connecting it with a clean one using an adaptor.

As-prepared $\mathrm{TaSe}_{2}$ nanosheets were observed using AFM to investigate the morphology and layer character. The image area $(40 \mu \mathrm{m} \times 40 \mu \mathrm{m})$ is illustrated in Figure 3a. A homodisperse solution was successfully fabricated. The corresponding cross-section analysis is shown in Figure 3b. The green dotted line denotes the average height, which showed that the thickness of the $2 \mathrm{H}-\mathrm{TaSe} 2$ sample is approximately $3-5 \mathrm{~nm}$; thus, the fabricated sample is a 4-7-layered structure (single-layered $\mathrm{TaSe}_{2}$ shows a thickness of around $0.75 \mathrm{~nm}[24,25])$.

(a)

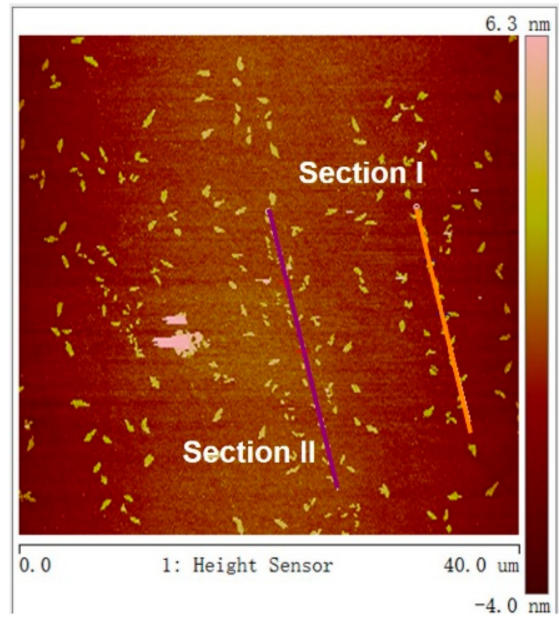

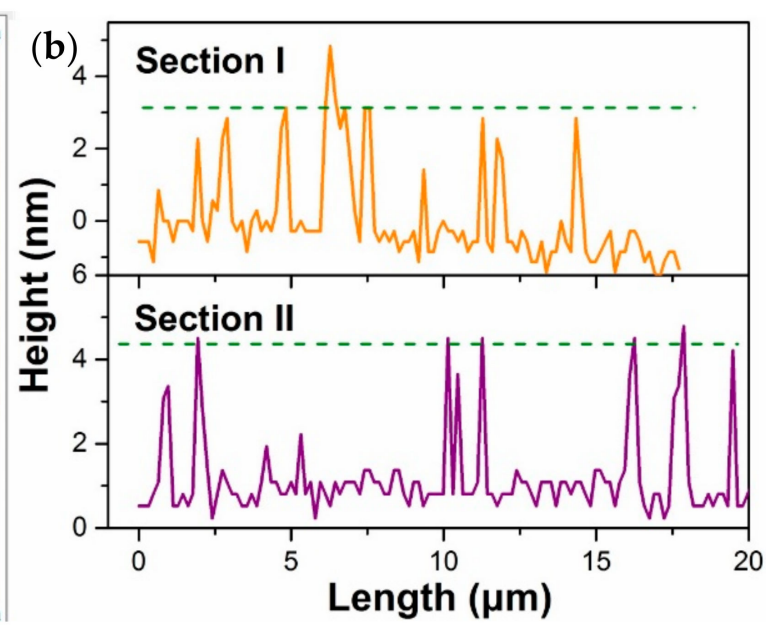

Figure 3. (a) Atomic force microscope (AFM) image of the $2 \mathrm{H}-\mathrm{TaSe}_{2}$ sample in a $40 \times 40 \mu \mathrm{m}$ region and (b) corresponding height. 
The phase of the $\mathrm{TaSe}_{2}$ sample was confirmed by investigating its Raman spectrum at room temperature using a laser source with an excitation of $532 \mathrm{~nm}$ (Renishaw inVia Raman microscope with the spectral resolution of $1 \mathrm{~cm}^{-1}$ ). The $2 \mathrm{H}-\mathrm{TaSe}_{2}$ sample in the metallic phase demonstrates hexagonal syngony of $D_{6 h}^{4}$ space group. $\mathrm{A}_{1 \mathrm{~g}}$ and $\mathrm{E}_{1 \mathrm{~g}}\left(\mathrm{E}_{2 \mathrm{~g}}\right)$ Raman active modes represent the out-of-plane and in-plain vibrational modes, respectively. Figure 4a shows that Raman peaks located at 140, 207, and $234 \mathrm{~cm}^{-1}$ correspond to $\mathrm{E}_{1 \mathrm{~g}}$, $\mathrm{E}_{2 \mathrm{~g}}$, and $\mathrm{A}_{1 \mathrm{~g}}$ modes, respectively. Compared with previous reports, some negligible shifts of peak position and intensity caused by the difference in layer numbers of $\mathrm{TaSe}_{2}$ nanosheets were observed $[25,26]$. Linear transmission spectra of the $\mathrm{TaSe}_{2}$ sample and sapphire substrate in Figure $4 \mathrm{~b}$ were examined using a spectrophotometer (U-3500) to show the broadband absorption at infrared band of metallic nanomaterial.
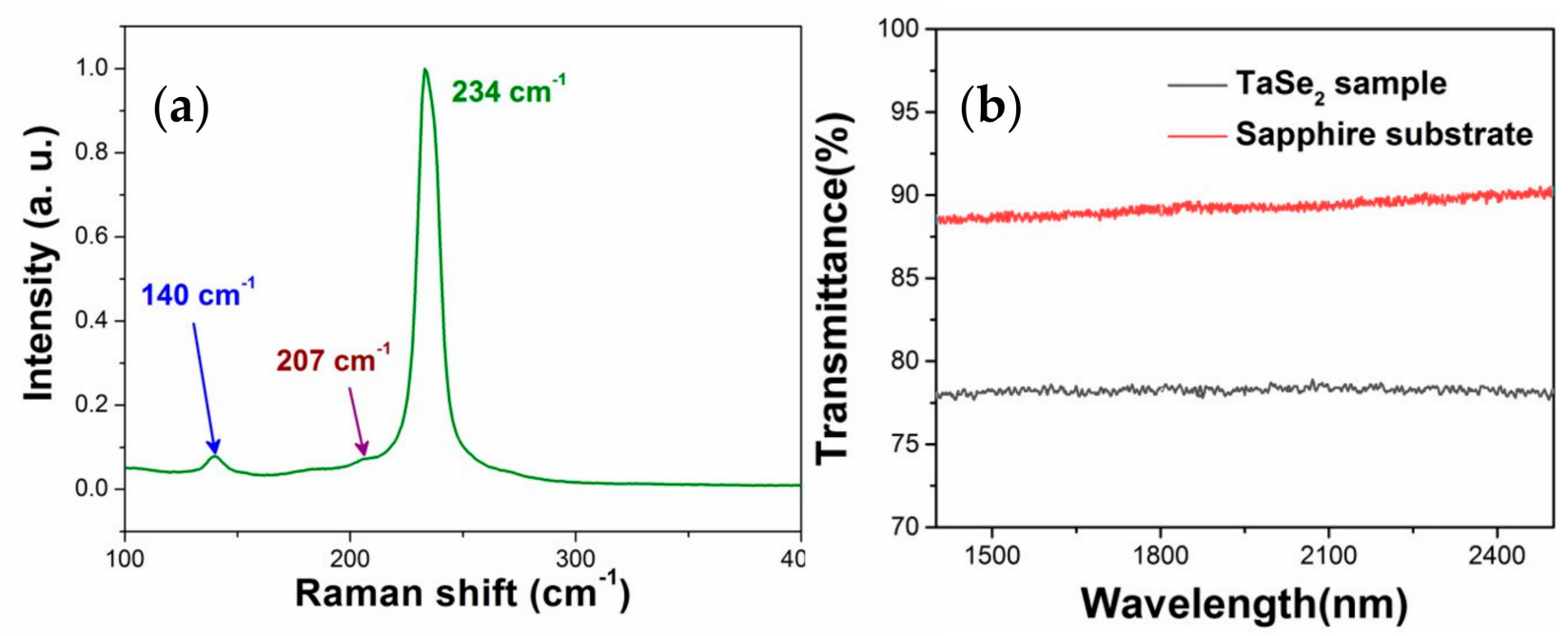

Figure 4. (a) Raman data of $2 \mathrm{H}-\mathrm{TaSe}_{2}$ nanosheets. (b) Linear transmittance of the sample and sapphire substrate.

An open-aperture Z-scan was applied to assess the nonlinear optical character of $2 \mathrm{H}-\mathrm{TaSe}_{2}$. A homemade pulsed fiber amplifier (wavelength, pulse width, and repetition rate of $1560 \mathrm{~nm}, 15 \mathrm{ps}$, and $1 \mathrm{MHz}$, respectively) was used to measure the Z-scan curve as follows (inset of Figure 5) [27]:

$$
T(z)=\sum_{m=0}^{\infty} \frac{\left(-\alpha_{N L} I_{0} L_{e f f}\right)^{m}}{(m+1)^{1.5}\left[\left(z / z_{0}\right)^{2}+1\right]^{m}} \approx 1-\frac{\alpha_{N L} I_{0} L_{e f f}}{2 \sqrt{2}\left[\left(z / z_{0}\right)^{2}+1\right]}+\frac{\left(\alpha_{N L} I_{0} L_{e f f}\right)^{2}}{3 \sqrt{3}\left[\left(z / z_{0}\right)^{2}+1\right]^{2}}
$$

where $L_{\text {eff }}$ is the effective length, $\alpha_{N L}$ is the nonlinear optical coefficient, $I_{0}$ is the power intensity, $z_{0}$ is the Rayleigh length, and $T$ is the normalized transmittance. The nonlinear optical coefficient $\alpha_{N L}$ was $(7.3 \pm 0.7) \mathrm{cm} / \mathrm{GW}$, according to the fitting result, which is comparable with the findings of other mature 2D materials [28]. According to the change in beam radius of the Gauss beam, the saturable absorption curve can be extracted based on Z-scan data, as illustrated in Figure 5. The modulation depth and saturation intensity were separately calculated at $9.6 \%$ and $12.7 \mu \mathrm{J} / \mathrm{cm}^{2}$, respectively, through data fitting [27]. The results showed that the metallic $2 \mathrm{H}-\mathrm{TaSe}_{2}$ sample can be a SA candidate for generating pulse lasers. 


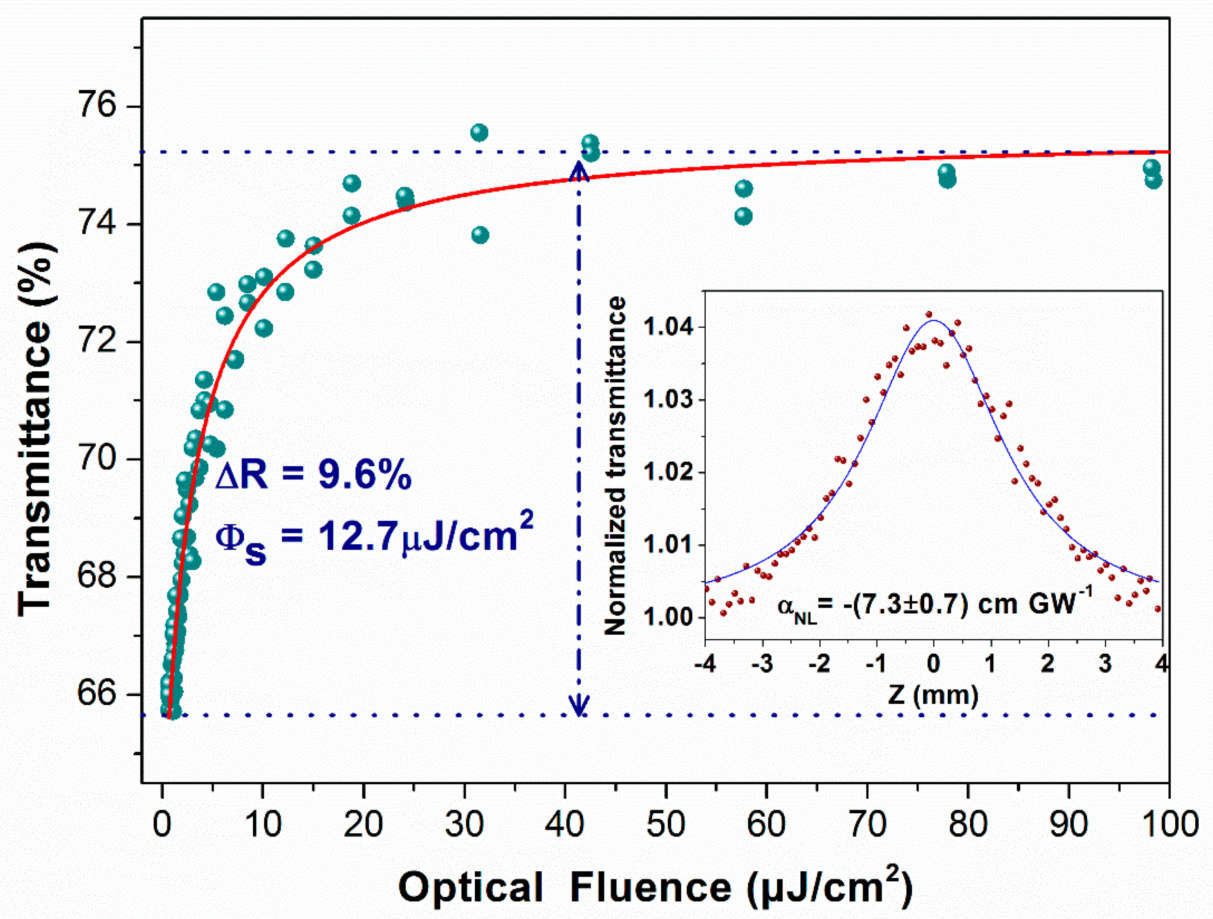

Figure 5. Saturable absorption curve of $2 \mathrm{H}-\mathrm{TaSe}_{2}$. (Note: The inset shows the open-aperture Zscan data).

\section{Experimental Setup}

The Q-switched all-fiber laser cavity based on $\mathrm{TaSe}_{2} \mathrm{SA}$ is illustrated in Figure 6. The laser cavity length, including the $0.5 \mathrm{~m}$-long and highly erbium-doped (EDF, LIEKKI: Er110-4-125) and else-tailed (single-mode fiber, SMF) fibers, was approximately $7.5 \mathrm{~m}$. As a commercial $980 \mathrm{~nm}$ laser diode (LD) with a maximum power of $550 \mathrm{~mW}$, the pump source is used via $980 / 1550 \mathrm{~nm}$ wavelength division multiplexing (WDM) to pump EDF with a dispersion parameter of $-12 \mathrm{ps} / \mathrm{nm} / \mathrm{km}$. A polarization controller (PC) and a polarization-independent isolator (PI-ISO) were applied to optimize cavity birefringence and ensure the unidirectional operation of the laser cavity, respectively. Moreover, $20 \%$ of the energy of an optical coupler (OC) is used to output laser signal. Given that the standard SMF shows a dispersion parameter of $18 \mathrm{ps} / \mathrm{nm} / \mathrm{km}$, the net cavity dispersion is calculated at $-0.153 \mathrm{ps}^{2}$.

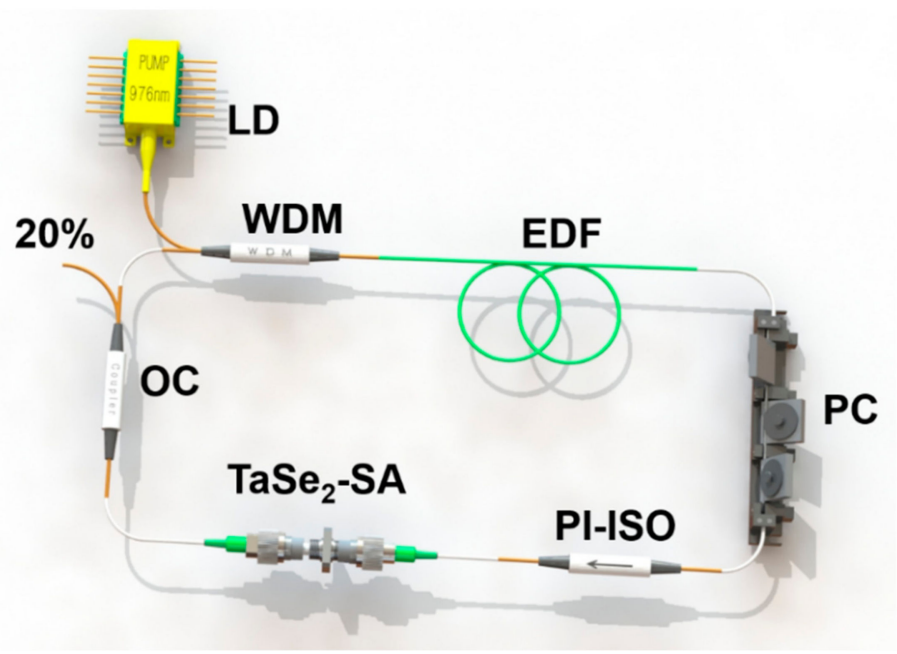

Figure 6. Experimental setup of the Q-switched fiber laser. 


\section{Results and Discussion}

A clean ferrule without deposition was first inserted into the fiber cavity to prove the optical modulation capability of the TaSe $\mathrm{T}_{2}$ nanomaterial. As a result, Q-switch was absent, except continuous wave $(\mathrm{CW})$, regardless of the pump power change or PC tuning. The output power was measured with a power meter (Thorlabs, PM100D), and its change versus pump power without $\mathrm{TaSe}_{2}$ is illustrated in Figure 7a (green dots). The slope efficiency was $5.06 \%$ with the maximum output power of $23.8 \mathrm{~mW}$ under a pump power of $500 \mathrm{~mW}$. The maximum output power decreased to $16.9 \mathrm{~mW}$ with a slope efficiency of $3.73 \%$ when the prepared $\mathrm{TaSe}_{2} \mathrm{SA}$ was inserted into the cavity due to the insertion loss induced by $\mathrm{TaSe}_{2} \mathrm{SA}$. The results indicated the successful deposition of $\mathrm{TaSe}_{2}$ materials onto the fiber ferrule.
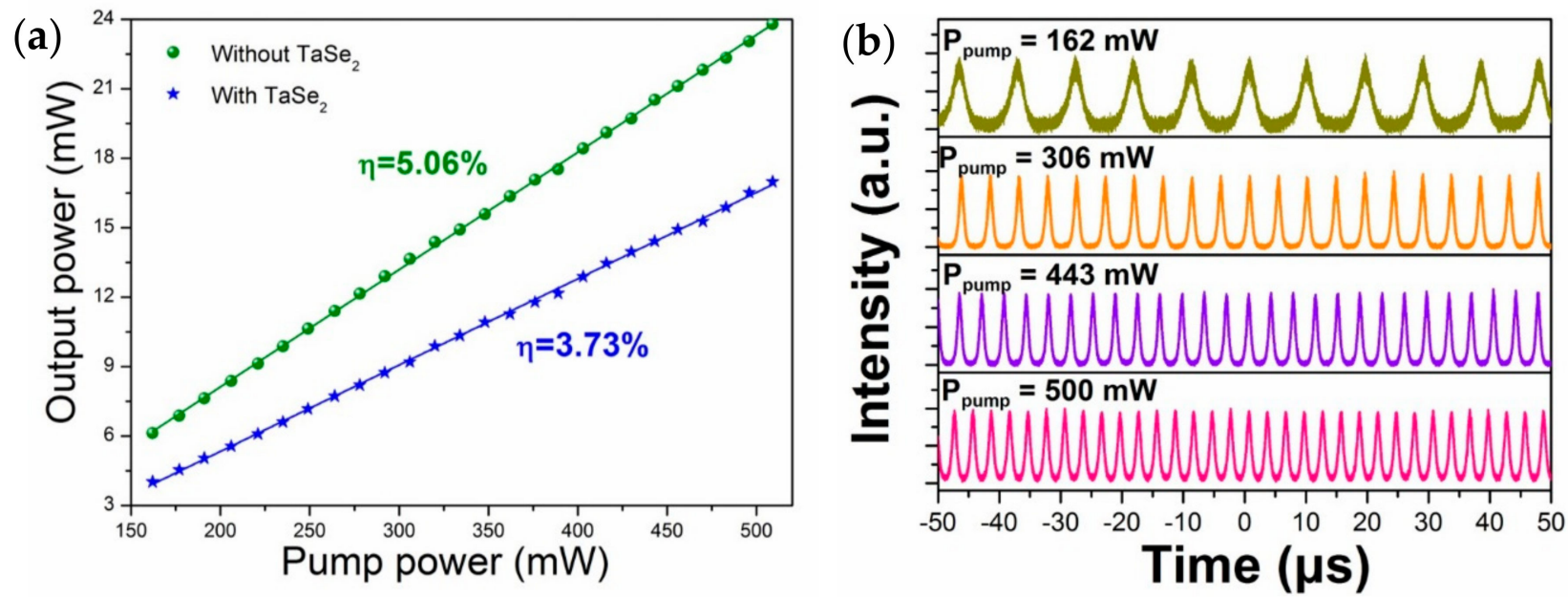

Figure 7. (a) Output power versus pump power with $\mathrm{TaSe}_{2}$ (green dots) and without $\mathrm{TaSe}_{2}$ (blue stars). (b) Stable pulse trains with different pump power values.

Stable and typical Q-switched pulses were observed when the pump power was increased to $160 \mathrm{~mW}$. Figure $7 \mathrm{~b}$ shows the output pulse trains with different pump power values. The evidently stable output pulses with the maximum pump power $(500 \mathrm{~mW})$ indicated the high thermal damage threshold of the metallic $\mathrm{TaSe}_{2}$ material. When the pump power increased from 160 to $500 \mathrm{~mW}$, the rate repetition increased from 28.4 to $89.9 \mathrm{kHz}$ but the pulse width reduced from 9.69 to $2.95 \mu \mathrm{s}$. The minimum pulse with a Gauss-pulse profile assumed and pulse width (repetition rate) that depend on the pump power are depicted in Figure 8a,b, respectively. The change mechanism can be explained by the population inversion. The increase in electron accumulation on the upper energy level with increasing pump power shortens the rising and following time of big pulse formed by the sudden release of stored energy released suddenly. As a result, the pulse width reduced and the rate repetition increased with the increment of pump power. The pulse energy and peak power at different pump power values can be easily calculated, as shown in Figure 8c. The maximum pulse energy and peak power were $188.9 \mathrm{~nJ}$ and $64 \mathrm{~W}$, respectively, at an average output power of $16.9 \mathrm{~mW}$.

The output spectrum is illustrated in Figure $8 \mathrm{~d}$. A dual wavelength with spectral separation of $24.1 \mathrm{~nm}$ was detected. Methods of multiwavelength fiber laser generation, such as subzero treatment [29], Mach-Zehnder interferometry element [30-32], and highly nonlinear materials [33,34], have been extensively investigated. Two oscillation wavelength peaks were located at 1532.2 and $1556.3 \mathrm{~nm}$ while the oscillation wavelength of the CW state demonstrated only one peak at $1564.6 \mathrm{~nm}$ in this study. Therefore, the generation of dual-wavelength Q-switched lasers was caused by the high nonlinearity of the nanomaterial $[33,34]$. 
(a)

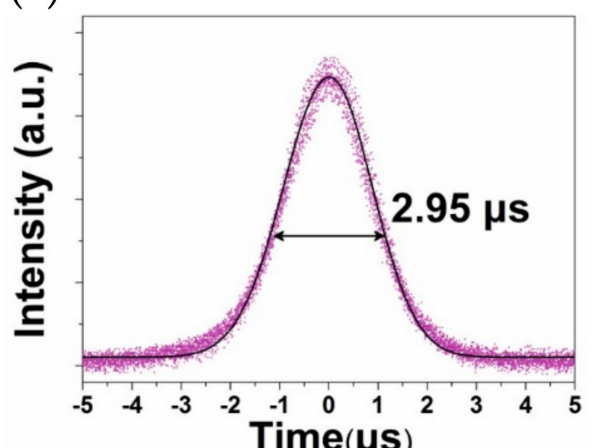

(c)

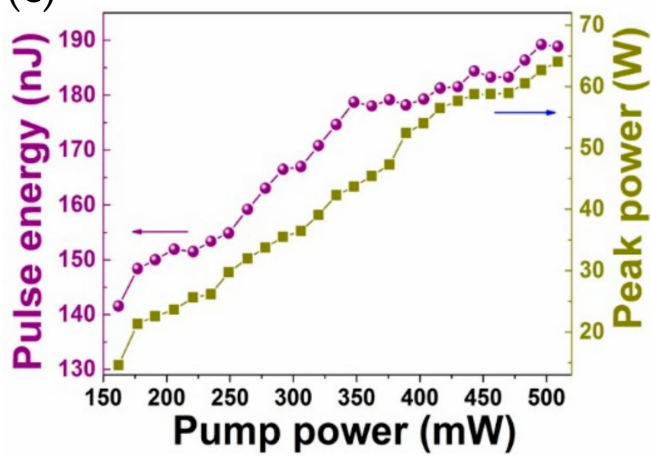

(b)

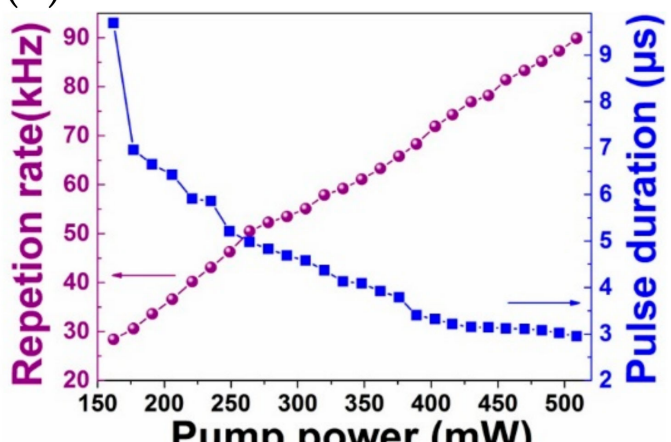

(d)

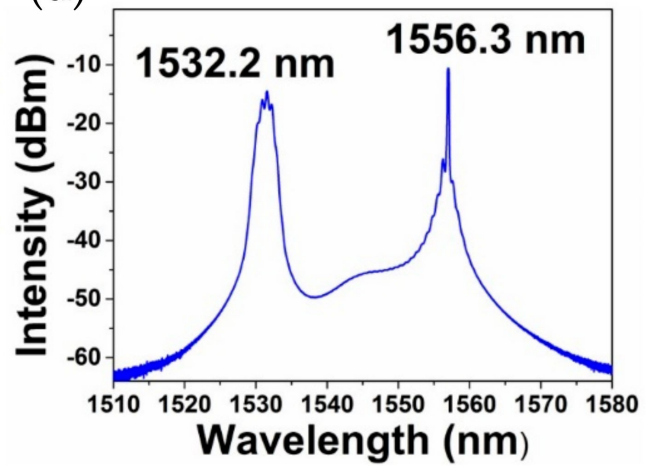

Figure 8. Laser performance: (a) Minimum pulse profile with a Gaussian-fitting standard deviation of $7.36 \times 10^{-4}$. (b) Pulse width and repetition rate versus pump power. (c) Pulse energy and peak power versus pump power. (d) Output spectrum with a pump power of $500 \mathrm{~mW}$.

Finally, we explored a $2 \mathrm{~h}$ output power at a pump power of $500 \mathrm{~mW}$ (Figure 9a). The standard deviation of measured output power is $0.004 \mathrm{~mW}$ and the corresponding RMS (standard deviation/average output power) is $0.02 \%$. Output spectra versus time at a pump power of $500 \mathrm{~mW}$ was also monitored (Figure 9b). The absence of evident vibrations indicated the excellent environmental stability of the Q-switched EDF lasers. Besides, Table 1 summarized the performance of Q-switched fiber laser using common semiconductor TMDs (including ternary TMD) materials as saturable absorber. By contrast, the $2 \mathrm{H}-\mathrm{TaSe}_{2}$ exhibited a comparable optical modulation ability. In view of the metallic band-structure, it could be deduced the $2 \mathrm{H}-\mathrm{TaSe}_{2}$ would be an except full-wave-band optical modulator.
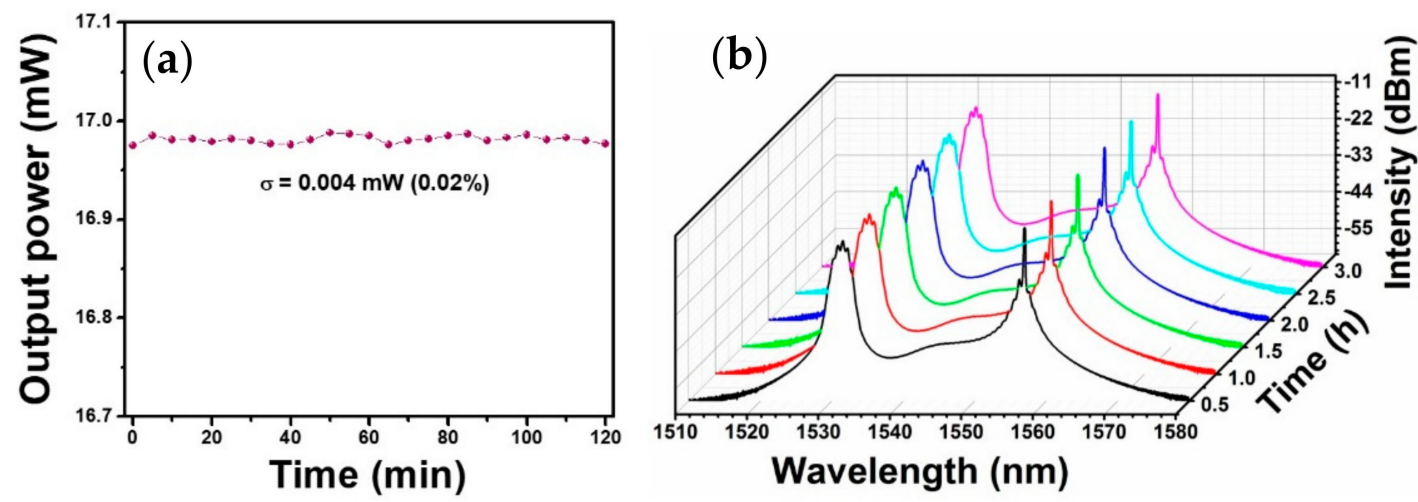

Figure 9. Long-term stability of (a) output power with the standard deviation of $0.004 \mathrm{~mW}$ and (b) output spectra at a pump power of $500 \mathrm{~mW}$. 
Table 1. Typical Q-switched EDF lasers using common transition metal dichalcogenides (TMDs) as saturable absorbers (SAs).

\begin{tabular}{|c|c|c|c|c|c|}
\hline Materials & Modulation Depth & Saturation Intensity & $\begin{array}{l}\text { Minimum Pulse } \\
\text { Width }(\mu s)\end{array}$ & Pulse Energy (nJ) & Ref. \\
\hline $\mathrm{MoS}_{2}$ & $29 \%$ & $4.53 \mathrm{MW} / \mathrm{cm}^{2}$ & 6 & 150 & [35] \\
\hline $\mathrm{WS}_{2}$ & $7.7 \%$ & $342.6 \mathrm{MW} / \mathrm{cm}^{2}$ & 0.1549 & 68.5 & [36] \\
\hline $\mathrm{MoSe}_{2}$ & $6.73 \%$ & $132.5 \mathrm{MW} / \mathrm{cm}^{2}$ & 4.04 & 365.9 & [37] \\
\hline $\mathrm{WSe}_{2}$ & $7.17 \%$ & $7 \mathrm{MW} / \mathrm{cm}^{2}$ & 1 & 29 & [38] \\
\hline $\mathrm{MoWSe}_{2}$ & $19.7 \%$ & $18.9 \mu \mathrm{J} / \mathrm{cm}^{2}$ & 1.53 & 151.4 & [27] \\
\hline $2 \mathrm{H}-\mathrm{TaSe}_{2}$ & $9.6 \%$ & $12.7 \mu \mathrm{J} / \mathrm{cm}^{2}$ & 2.95 & 188.9 & This work \\
\hline
\end{tabular}

\section{Conclusions}

A novel $2 \mathrm{H}-\mathrm{TaSe}_{2}$ with a metallic electronic band structure was used as a SA to generate Q-switched fiber laser. The nonlinear optical coefficient, modulation depth, and saturation intensity were $(7.3 \pm 0.7) \mathrm{cm} / \mathrm{GW}, 9.6 \%$, and $12.7 \mu \mathrm{J} / \mathrm{cm}^{2}$, respectively, via open-aperture Z-scan measurement. We demonstrated a dual-wavelength Q-switched fiber laser with a minimum pulse width of $2.95 \mu$ s based on the prepared $2 \mathrm{H}-\mathrm{TaSe}_{2} \mathrm{SA}$. The maximum pulse energy of $188.9 \mathrm{~nJ}$ and maximum peak power of $64 \mathrm{~W}$ were calculated at the maximum repetition rate of $89.9 \mathrm{kHz}$. The excellent nonlinear optical modulating ability of $2 \mathrm{H}-\mathrm{TaSe}_{2}$ verifies its potentiality in novel optoelectronic applications as a metallic TMD material.

Author Contributions: Investigation, L.Y.; writing—original draft preparation, R.Z. and T.X.; writingreview and editing, D.W. and X.L.; supervision, Q.N. and S.D. All authors have read and agreed to the published version of the manuscript.

Funding: This work is supported by National Natural Science Foundation of China (61905125, 61905124), China Postdoctoral Science Foundation (2018M642387), and K. C. Wong Magna Fund in Ningbo University.

Institutional Review Board Statement: Not applicable.

Informed Consent Statement: Not applicable.

Data Availability Statement: Data sharing is not applicable to this article.

Conflicts of Interest: The authors declare no conflict of interest.

\section{References}

1. Xian, T.; Zhan, L.; Gao, L.; Zhang, W.; Zhang, W. Passively Q-switched fiber lasers based on pure water as the saturable absorber. Opt. Lett. 2019, 44, 863-866. [CrossRef] [PubMed]

2. Wang, Z.Q.; Zhan, L.; Wu, J.; Zou, Z.; Zhang, L.; Qian, K.; He, L.; Fang, X. Self-starting ultrafast fiber lasers mode-locked with alcohol. Opt. Lett. 2015, 40, 3699-3702. [CrossRef] [PubMed]

3. Keller, U. Recent developments in compact ultrafast lasers. Nat. Cell Biol. 2003, 424, 831-838. [CrossRef] [PubMed]

4. Guo, B. 2D noncarbon materials-based nonlinear optical devices for ultrafast photonics. Chin. Opt. Lett. 2018, 16, 020004. [CrossRef]

5. Sun, Z.; Martinez, A.; Wang, F. Optical modulators with 2D layered materials. Nat. Photon. 2016, 10, 227-238. [CrossRef]

6. Wu, D.; Peng, J.; Cai, Z.; Weng, J.; Luo, Z.; Chen, N.; Xu, H. Gold nanoparticles as a saturable absorber for visible $635 \mathrm{~nm}$ Q-switched pulse generation. Opt. Express 2015, 23, 24071-24076. [CrossRef]

7. Pang, C.; Li, R.; Li, Z.; Dong, N.; Cheng, C.; Nie, W.; Böttger, R.; Zhou, S.; Wang, J.; Chen, F. Lithium Niobate Crystal with Embedded Au Nanoparticles: A New Saturable Absorber for Efficient Mode-Locking of Ultrafast Laser Pulses at $1 \mu \mathrm{m}$. Adv. Opt. Mater. 2018, 6, 1800357. [CrossRef]

8. Liu, W.-J.; Liu, M.L.; Lin, S.; Liu, J.C.; Lei, M.; Wu, H.; Dai, C.Q.; Wei, Z.-Y. Synthesis of high quality silver nanowires and their applications in ultrafast photonics. Opt. Express 2019, 27, 16440-16448. [CrossRef]

9. Liu, M.; Liu, W.-J.; Hou, H.; Ouyang, Y.; Lei, M.; Wei, Z.-Y. Silver nanowires with different concentration for Q-switched fiber lasers. Opt. Mater. Express 2020, 10, 187-197. [CrossRef]

10. XSun, X.; Shi, B.; Wang, H.; Lin, N.; Liu, S.; Yang, K.; Zhang, B.; He, J. Optical Properties of 2D 3R Phase Niobium Disulfide and Its Applications as a Saturable Absorber. Adv. Opt. Mater. 2020, 8, 1901181. [CrossRef]

11. Wang, Q.H.; Kalantar-Zadeh, K.; Kis, A.; Coleman, J.N.; Strano, M.S. Electronics and optoelectronics of two-dimensional transition metal dichalcogenides. Nat. Nanotechnol. 2012, 7, 699-712. [CrossRef] [PubMed] 
12. Xi, X.; Wang, Z.; Zhao, W.; Park, J.-H.; Law, K.T.; Berger, H.; Forró, L.; Shan, J.; Mak, K.F. Ising pairing in superconducting NbSe 2 atomic layers. Nat. Phys. 2016, 12, 139-143. [CrossRef]

13. Soluyanov, A.A.; Gresch, D.; Wang, Z.; Wu, Q.; Troyer, M.; Dai, X.; Bernevig, B.A. Type-II Weyl semimetals. Nature 2015, 527, 495-498. [CrossRef] [PubMed]

14. Samnakay, R.; Wickramaratne, D.; Pope, T.R.; Lake, R.K.; Salguero, T.T.; Balandin, A.A. Zone-Folded Phonons and the Commensurate-Incommensurate Charge-Density-Wave Transition in 1T-TaSe 2 Thin Films. Nano. Lett. 2015, 15, 2965-2973. [CrossRef] [PubMed]

15. Manchanda, P.; Sharma, V.; Yu, H.; Sellmyer, D.J.; Skomski, R. Magnetism of Ta dichalcogenide monolayers tuned by strain and hydrogenation. Appl. Phys. Lett. 2015, 107, 032402. [CrossRef]

16. Renteria, J.; Samnakay, R.; Jiang, C.; Pope, T.R.; Goli, P.; Yan, Z.; Wickramaratne, D.; Salguero, T.T.; Khitun, A.G.; Lake, R.K.; et al. All-metallic electrically gated $2 \mathrm{H}-\mathrm{TaSe}_{2}$ thin-film switches and logic circuits. J. Appl. Phys. 2014, 115, 034305. [CrossRef]

17. Kresse, G.; Hafner, J. Ab initio molecular dynamics for liquid metals. Phys. Rev. B 1993, 47, 558-561. [CrossRef]

18. Kresse, G.; Hafner, J. Ab initio molecular dynamics for open-shell transition metals. Phys. Rev. B 1993, 48, 13115-13118. [CrossRef]

19. Kresse, G.; Furthmüller, J. Efficiency of ab-initio total energy calculations for metals and semiconductors using a plane-wave basis set. Comput. Mater. Sci. 1996, 6, 15-50. [CrossRef]

20. Blochl, P.E. Projector augmented-wave method. Phys. Rev. B 1994, 50, 17953-17979. [CrossRef]

21. Perdew, J.P.; Burke, K.; Ernzerhof, M. Generalized Gradient Approximation Made Simple. Phys. Rev. Lett. 1996, 77, 3865-3868. [CrossRef] [PubMed]

22. Monkhorst, H.J.; Pack, J.D. Special points for Brillouin-zone integrations. Phys. Rev. B 1976, 13, 5188-5192. [CrossRef]

23. Tsoutsou, D.; Aretouli, K.E.; Tsipas, P.; Marquez-Velasco, J.; Xenogiannopoulou, E.; Kelaidis, N.; Giamini, S.A.; Dimoulas, A. Epitaxial 2D MoSe $2\left(\mathrm{HfSe}_{2}\right)$ Semiconductor/2D TaSe 2 Metal van der Waals Heterostructures. ACS Appl. Mater. Interfaces 2016, 8, 1836-1841. [CrossRef] [PubMed]

24. Kuchinskii, E.Z.; Nekrasov, I.A.; Sadovskii, M.V. Electronic structure of two-dimensional hexagonal diselenides: Charge density waves and pseudogap behavior. J. Exp. Theor. Phys. 2012, 114, 671-680. [CrossRef]

25. Hajiyev, P.; Cong, C.; Qiu, C.; Yu, T. Contrast and Raman spectroscopy study of single- and few-layered charge density wave material: $2 \mathrm{H}-\mathrm{TaSe}_{2}$. Sci. Rep. 2013, 3, 2593. [CrossRef] [PubMed]

26. Wang, J.; Guo, C.; Guo, W.; Wang, L.; Shi, W.; Chen, X. Tunable 2H-TaSe 2 room-temperature terahertz photodetector. Chin. Phys. $B$ 2019, 28, 046802. [CrossRef]

27. Yang, L.; Yan, B.; Zhao, R.; Wu, D.; Xu, T.; Nie, Q.; Dai, S. Output energy enhancement in a dual-wavelength Q-switched fiber laser based on a ternary MoWSe ${ }_{2}$ saturable absorber. Opt. Fiber Technol. 2020, 57, 102214. [CrossRef]

28. Wang, K.; Feng, Y.; Chang, C.; Zhan, J.; Wang, C.; Zhao, Q.; Coleman, J.N.; Zhang, L.; Blau, W.J.; Wang, J. Broadband ultrafast nonlinear absorption and nonlinear refraction of layered molybdenum dichalcogenide semiconductors. Nanoscale 2014, 6, 10530-10535. [CrossRef]

29. Yamashita, S.; Hotate, K. Multiwavelength erbium-doped fibre laser using intracavity etalon and cooled by liquid nitrogen. Electron. Lett. 1996, 32, 1298-1299. [CrossRef]

30. Soltanian, M.R.K.; Amiri, I.; Alavi, S.E.; Ahmad, H. Dual-Wavelength Erbium-Doped Fiber Laser to Generate Terahertz Radiation Using Photonic Crystal Fiber. J. Light. Technol. 2015, 33, 5038-5046. [CrossRef]

31. Soltanian, M.R.K.; Ahmad, H.; Khodaie, A.; Amiri, I.; Ismail, M.F.I.M.F.; Harun, S.W. A Stable Dual-wavelength Thulium-doped Fiber Laser at $1.9 \mu \mathrm{m}$ Using Photonic Crystal Fiber. Sci. Rep. 2015, 5, 14537. [CrossRef] [PubMed]

32. Ahmad, H.; Soltanian, M.R.K.; Pua, C.H.; Zulkifli, M.Z.; Harun, S.W. Narrow Spacing Dual-Wavelength Fiber Laser Based on Polarization Dependent Loss Control. IEEE Photon. J. 2013, 5, 1502706. [CrossRef]

33. Zhao, R.; He, J.; Su, X.; Nie, H.; Yang, K.; Wang, Y.; Sun, X.; Zhang, B. Tunable High-Power Q-Switched Fiber Laser Based on BP-PVA Saturable Absorber. IEEE J. Sel. Top. Quantum Electron. 2017, 24, 1-5. [CrossRef]

34. Zhao, X.; Zheng, Z.; Liu, L.; Liu, Y.; Jiang, Y.; Yang, X.; Zhu, J. Switchable, dual-wavelength passively mode-locked ultrafast fiber laser based on a single-wall carbon nanotube modelocker and intracavity loss tuning. Opt. Express 2011, 19, 1168-1173. [CrossRef]

35. Chen, J.-H.; Deng, G.-Q.; Yan, S.-C.; Li, C.; Xi, K.; Xu, F.; Lu, Y.-Q. Microfiber-coupler-assisted control of wavelength tuning for Q-switched fiber laser with few-layer molybdenum disulfide nanoplates. Opt. Lett. 2015, 40, 3576-3579. [CrossRef]

36. Chen, H.; Chen, Y.; Yin, J.; Zhang, X.; Guo, T.; Yan, P. High-damage-resistant tungsten disulfide saturable absorber mirror for passively Q-switched fiber laser. Opt. Express 2016, 24, 16287-16296. [CrossRef]

37. Chen, B.; Zhang, X.; Wu, K.; Wang, H.; Wang, J.; Chen, J. Q-switched fiber laser based on transition metal dichalcogenides MoS 2 , $\mathrm{MoSe}_{2}, \mathrm{WS}_{2}$, and $\mathrm{WSe}_{2}$. Opt. Express 2015, 23, 26723-26737. [CrossRef]

38. Guo, C.; Chen, B.; Wang, H.; Wu, K.; Chen, J. Investigation on Stability of WSe $\mathrm{H}_{2}-\mathrm{PVA}$ in an All Polarization Maintaining Q-Switched Fiber Laser. Chin. J. Laser. 2017, 44, 0703018. 